\title{
HDPE 100 Boruların Sıcak Eleman Alın Kaynağıyla Birleştirilmesinde Kaynak Sıcaklığı Parametresinin Birleştirme Mukavemetine Etkisi
}

\author{
${ }^{* 1}$ Hüseyin Uzun ve ${ }^{2}$ Ayșe Gül Kocaman \\ ${ }^{* 1}$ Sakarya Uygulamalı Bilimler Üniversitesi, Esentepe Kampüsü, Sakarya, Turkey \\ ${ }^{2}$ Sakarya Üniversitesi, Esentepe kampüsü, Sakarya, Turkey
}

\section{Özet}

Bu çalışmada, doğal gaz ve içme suyu dağıtım hatlarında, metalik boruların yerini alan yüksek yoğunluklu PE 100 boruların, sıcak elaman alın kaynağı yöntemiyle farklı kaynak sıcaklıklarında birleştirilmesi amaçlanmıştır. Kaynak sıcaklığının birleştirme mukavemetine etkisi incelenerek, en uygun optimum kaynak sıcaklık değerinin belirlenmesi hedeflenmiştir. Bu amaçla birleştirilen HDPE 100 borularının çekme testi gerçekleştirilmiş̧ir. Deneysel çalışmaların sonucu olarak, yanaştırma ve birleştirme basınçları 6 bar, 1sıtıcının yanaştırma süresi 25 sn, ssıtma süresi 120 sn, 1sıtıcının çıkartılma süresi 6 sn, birleştirme süresi 6 sn ve basınç altında soğuma süresi 12 sn olarak seçilen sıcak eleman alın kaynak parametreleri için en yüksek birleştirme mukavemeti veren kaynak sıcaklı̆̆ının, $225^{\circ} \mathrm{C}$ olduğu tespit edilmiştir.

Anahtar Kelimeler: HDPE 100 boru, sıcak elaman alın kaynağı, kaynak sıcaklığı

\section{Effect of Welding Temperature on HDPE 100 Pipe Hot Butt Weld Joint Strength}

\begin{abstract}
In present study, hot butt welding of similar HDPE 100 pipes used for natural gas and drinking water pipe lines replaced of metallic pipes was performed in order to investigate the effect of welding temperature on joint strength. The tensile test was carried out to achieve joint strength of HDPE 100 welded pipes. The experimental results reveal that the most suitable welding temperature, which gave the highest joint strength, was $225{ }^{\circ} \mathrm{C}$ at the following hot butt welding parameters: alignment and joining pressures of 6 bar, alignment time of $25 \mathrm{~s}$, heating-up time of $120 \mathrm{~s}$, change over time of $6 \mathrm{~s}$, joining time of $6 \mathrm{~s}$ and cooling time of $12 \mathrm{~s}$.
\end{abstract}

Key words: Polyethylene (PE 100) pipe, hot butt welding, welding temperature

\section{Giriş}

Son yıllarda, doğal gaz ve içme suyu dağıtım hatlarında metalik boru sistemlerinin yerine, polietilen (PE) boruların tercih edildiğini görmekteyiz. Polietilen borularda da geliştirilen üstün özelliklerinden dolayı yüksek yoğunluklu PE 100 (HDPE 100) malzemesi öne çıkmaktadır. HDPE 100 malzemesi taşınabilme ve montaj kolaylığı, yüksek korozyon direnci, iyi birleştirilebilme

*Corresponding author: Address: Sakarya Uygulamalı Bilimler Üniversitesi, 54187, Sakarya TURKEY. E-mail address: huzun@sakarya.edu.tr, Phone: +902642956489 
kabiliyeti, yüksek dayanıklılık, darbe direncinin yüksek olması, çatlamaya karşı dirençli olması, esnek olması, uzun ömürlü olması, su ile kimyasal etkileşiminin olmayışı gibi özellikleri nedeniyle tercih edilmektedir. HDPE 100 (Minimum gerekli mukavemet, MRS = $10 \mathrm{MPa}$; malzemenin $20^{\circ} \mathrm{C}^{\prime}$ de en az 50 yıl süreyle $10 \mathrm{MPa}$ işletme basıncında sorunsuz çalışması demektir) malzemesinin güneş ışınlarına dayanımını artırmak amacıyla karbon siyahı katkılı olarak üretilmektedirler. Toprak içerisine döşenen bu borularda, katodik koruma gibi bir önlemin alınmasına gerek duyulmaz, tuzlu deniz suyundan olumsuz etkilenmez, içme suyunun tat ve kokusunu değiştirmez. Ayrıca HDPE 100 kalitesinde üretilen bu borular sayesinde, daha düşük et kalınlıkları ile daha yüksek basınçlarda çalışma olanağı elde edilir [1-4].

HDPE 100 boruların birleştirilmesinde en yaygın kullanılan birleştirme teknikleri, sıcak alın ve elektrofüzyon kaynak yöntemleridir. Farklı et kalınlığındaki ve farklı özelliklere sahip HDPE boruların birleştirilmesinde elektrofüzyon kaynak yöntemi tercih edilirken, aynı et kalınlığına ve aynı özelliklere sahip HDPE boruların birleştirilmesinde de sıcak eleman alın kaynağı kullanılmaktadır [5-7].

Sıcak eleman alın kaynağında, birleştirilecek boru alın yüzeyleri, 1sıtıcı plaka vasıtasıyla kaynak sıcaklığına ulaştırılır. Isıtıcı plakanın, ısınan yüzeylerden uzaklaştırılmasını takiben, boru alın yüzeylerinin belirlenen kaynak süresince belirli bir basınç altında tutulmasıyla birleştirilme işlemi gerçekleştirilir. İstenilen niteliklere veya dayanıma sahip bir birleştirme demek, en az orijinal ana borunun sahip olduğu dayanıma sahip bir birleştirme dayanımının sağlanması demektir. Bu nedenle kaynak sıcaklığı, kaynak basıncı ve kaynak süresi gibi kaynak parametrelerinin çok hassas bir şekilde ayarlanması zorunludur $[8,9]$.

Bu çalışmada, doğal gaz ve içme suyu dağıtım hatlarında kullanılan HDPE 100 boruların, sıcak elaman alın kaynak yöntemiyle farklı kaynak sıcaklıklarında birleştirilerek, birleştirme mukavemetine göre, kaynak parametreleriyle uyumlu en uygun optimum kaynak sıcaklık değerinin belirlenmesi hedeflenmiştir.

\section{Deneysel Çalışmalar}

Sicak elaman alın kaynak yöntemiyle birleştirilecek HDPE 100 borunun özellikleri Tablo 1'de verilmiştir. Birleştirilecek borunun et kalınlığ 10 mm, dış çapı $Ø 120 \mathrm{~mm}$ ve boyu $200 \mathrm{~mm}$ olarak seçilmiştir.

İlk aşamada birleştirilecek PE 100 borular, 200 mm boyunda elektrikli testere yardımı ile kesildi. Boruların birleşme kesit yüzeyleri, aynı eksen doğrultusunda birbirine dik ve paralel temas edecek şekilde, kaynak makinasına konumlandırıp sıkıştırıldı. Sıcak eleman alın kaynak makinasıyla yapılan birleştirme işlemi, Tablo 2'de verilen kaynak parametreleri kullanılarak ve Şekil 2'de gösterilen basınç-zaman grafiği doğrultusunda gerçekleştirilmiştir.

Birinci aşamada, tıraşlama bıçaklarıyla her iki boru yüzeyi tıraşlanmıştır. Bıçaklar alındıktan sonra yüzeylerdeki çapaklar temizlenmiş ve birleştirme alın yüzeyleri alkollü mendil ile silinmiştir. 
İkinci aşamada, birleştirme yüzeyleri arasına, Tablo 2'de verilen kaynak sıcaklık değerine göre 1sıtılmış plaka yerleştirilmiştir. Önce birleştirme yüzeyleri $\mathrm{P}_{1}$ basıncı altında birbirine yanaştırılarak $\mathrm{t}_{1}$ süresince belirli bir dudak yüksekliği $(1.5 \mathrm{~mm})$ oluşuncaya kadar bekletilmiş ve basınç sıfira (ara yüzey basıncına) indirilerek $\mathrm{t}_{2}$ süresince bekletilmiştir (Şekil 1).

Üçüncü aşamada, birleştirme yüzeyleri arasından ısıtıcı plaka, birleşme bölgelerine zarar vermeden t3 süresi gibi kısa bir sürede, çok hızlı bir şekilde çıkartılmıştır (Şekil 1).

Dördüncü ve son aşamada ise 1sıtıcı plakanın çıkartılmasından sonra borular birbirine çok kısa bir sürede $\left(\mathrm{t}_{4}\right)$ hemen yanaştırılmıştır. Cihaz $\mathrm{P}_{3}$ basınç değerine ayarlanarak, bu basınçta ve $\mathrm{t}_{5}$ süresince bekletilmiş ve birleştirme işlemi gerçekleştirilmiştir (Şekil 1).

Sadece kaynak sıcaklıkları değiştirilerek, diğer kaynak parametreleri sabit tutulup, sıcak plaka kaynak işlemi gerçekleştirilmiştir. $200^{\circ} \mathrm{C}, 225^{\circ} \mathrm{C}$ ve $250^{\circ} \mathrm{C}$ olmak üzere, üç farklı kaynak sicaklık değeri kullanılmıştır (Tablo 2). Aynı kaynak parametreleri kullanılarak, iki adet boru birleştirme işlemi yapılmıştır. Toplamda üç farklı kaynak sıcaklığı için 6 adet boru birleştirilmiştir.

Tablo 1. HDPE 100 boru malzemesinin mekanik ve fiziksel özellikleri

\begin{tabular}{cccccc}
\hline Birleştirilecek & \multicolumn{4}{c}{ Mekanik ve Fiziksel Özellikler } \\
Boru & MRS & Yoğunluk, $\left(23^{\circ} \mathrm{C}\right.$ & Kopma Uzaması & Elastisite Modülü & Karbon Siyahı \\
Malzemesi & $(\mathrm{MPa})$ & de $)\left(\mathrm{g} / \mathrm{cm}^{3}\right)$ & $(\%)$ & $(\mathrm{MPa})$ & Miktarı $(\%)$ \\
HDPE 100 & 10 & $>0,950$ & min. 350 & $>1000$ & $2-2.5$ \\
\hline
\end{tabular}

Tablo 2. Sicak eleman alın kaynak parametreleri

\begin{tabular}{cccccccc}
\hline $\begin{array}{c}\text { Kaynak } \\
\text { sicaklı̆̆ } \\
\mathrm{T}\left({ }^{\circ} \mathrm{C}\right)\end{array}$ & $\begin{array}{c}\text { Yanaştırma } \\
\text { Basınc1 } \\
\left(\mathrm{P}_{1}\right)(\mathrm{bar})\end{array}$ & $\begin{array}{c}\text { Birleştirme } \\
\text { Basınc1 }\left(\mathrm{P}_{3}\right) \\
(\mathrm{bar})\end{array}$ & $\begin{array}{c}\text { Yanaştırma } \\
\text { süresi }\left(\mathrm{t}_{1}\right) \\
(\mathrm{sn})\end{array}$ & $\begin{array}{c}\text { Isıtma } \\
\text { süresi } \\
\left(\mathrm{t}_{2}\right)(\mathrm{sn})\end{array}$ & $\begin{array}{c}\text { Isıtıcı çıkarma } \\
\text { süresi }\left(\mathrm{t}_{3}\right)(\mathrm{sn})\end{array}$ & $\begin{array}{c}\text { Birleştirme } \\
\text { süresi }\left(\mathrm{t}_{4}\right) \\
(\mathrm{sn})\end{array}$ & $\begin{array}{c}\text { Soğutma } \\
\text { süresi }\left(\mathrm{t}_{5}\right) \\
(\mathrm{sn})\end{array}$ \\
\hline 200 & 6 & 6 & 25 & 120 & 6 & 6 & 12 \\
225 & 6 & 6 & 25 & 120 & 6 & 6 & 12 \\
250 & 6 & 6 & 25 & 120 & 6 & 6 & 12 \\
\hline
\end{tabular}

Tinius Olsen H25KS marka çekme cihazı yardımıyla birleştirilen PE boru numunelerine çekme deneyi uygulanmıştır. TS ISO 13953 standardında verilen geometrik ölçülere göre çekme deneyi numunesi hazırlanmıştır. Şekil 2'de sıcak levha alın kaynağıyla birleştirilen PE 100 borudan hazırlanmış çekme deneyi numunesi ebatları gösterilmektedir. 


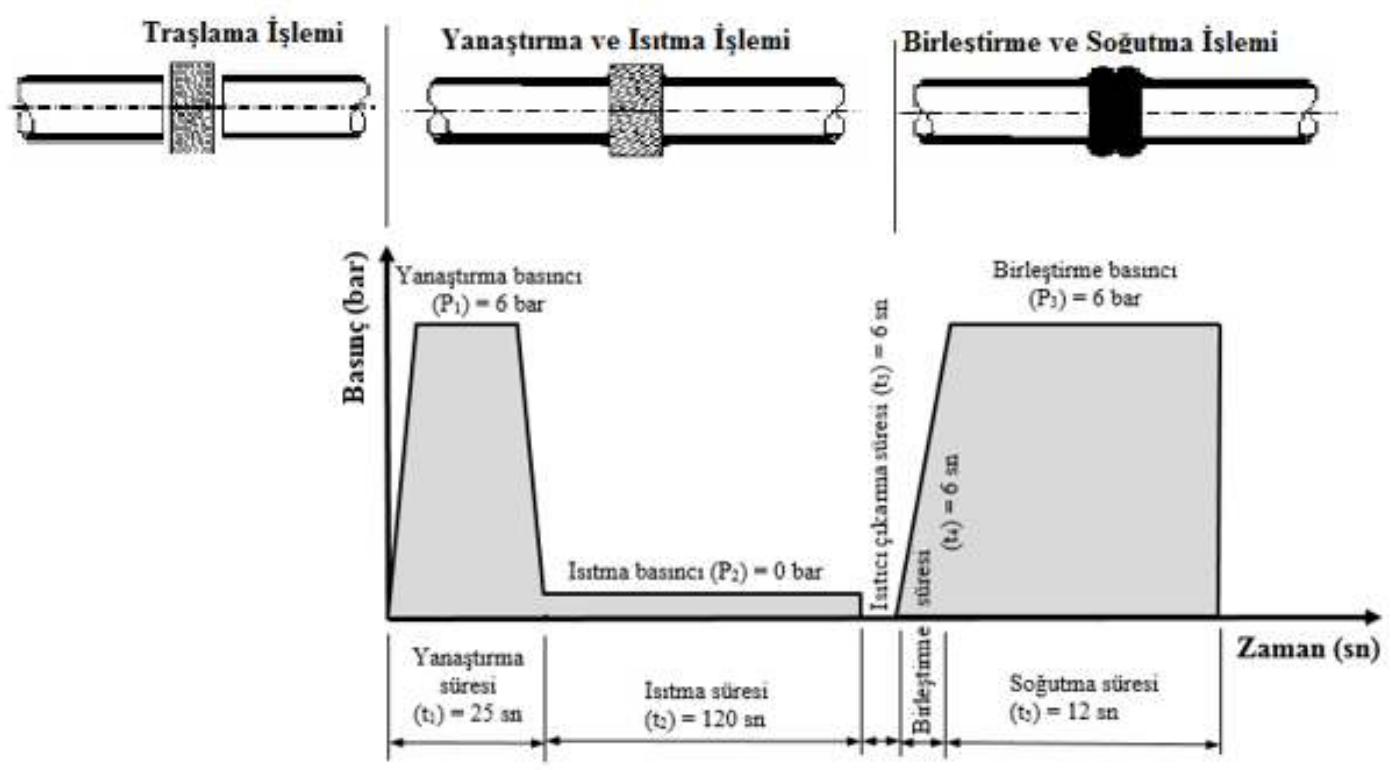

Şekil 1. Sıcak eleman alın kaynak işleminin uygulama aşaması

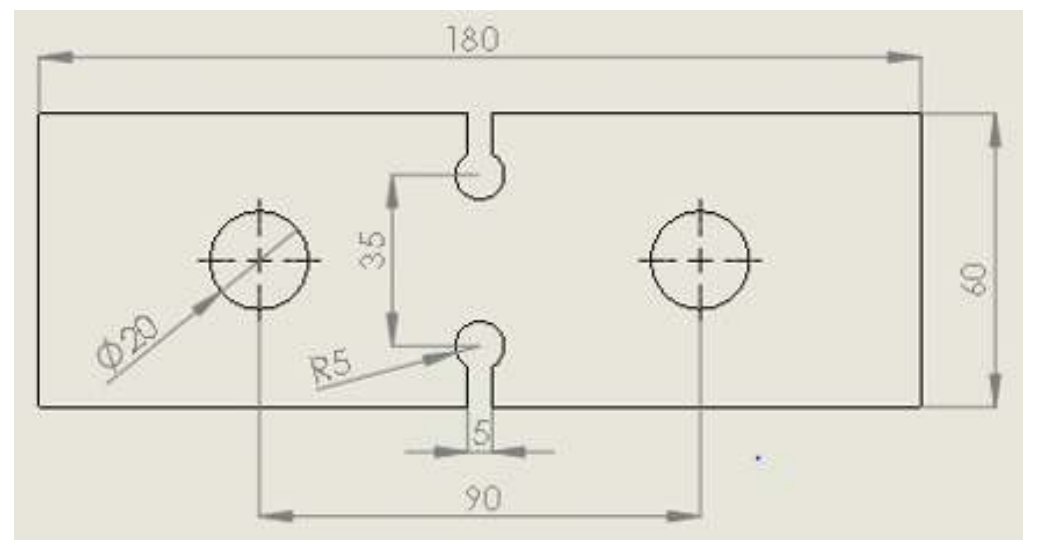

Şekil 2. Çekme deneyinde kullanılan test numunesinin geometrik şekli ve ebatları

\section{Sonuçlar ve İrdeleme}

Şekil 3'de sıcak elaman alın kaynak yöntemiyle birleştirilen HDPE 100 borunun, dış birleştirme bölgesine ait dudak bölgesinin makroskobik fotoğrafı görülmektedir. Dış dudak görünümü, yapılan birleştirme işleminin başarıyla gerçekleştiğini göstermektedir. Fakat üç farklı kaynak sıcaklığı parametresi kullanılarak yapılan birleştirme işlemlerinde, hangi kaynak sıcaklığı parametresinin daha etkin olduğunu söylemek mümkün gözükmemektedir. Hemen hemen makroskobik dış görünüş, her üç kaynak sıcaklığı kullanılarak yapılan birleştirmelerde birbirine çok benzemektedir. O nedenle farklı kaynak sıcaklığı kullanılarak birleştirilen her üç borunun hangi kaynak sıcaklı̆̆ının daha etkin olduğunu belirlemek için çekme testine gereksinim duyulmaktadır. 
Şekil 4'te sıcak eleman alın kaynağı ile birleştirilen borularda oluşan dudak geometrisi ve bu bölgenin tanımlanması gösterilmektedir. Yapılan tanımlamaya göre bu çalışma kapsamında birleştirilen HDPE 100 boruların dudak geometrileri verilecektir.

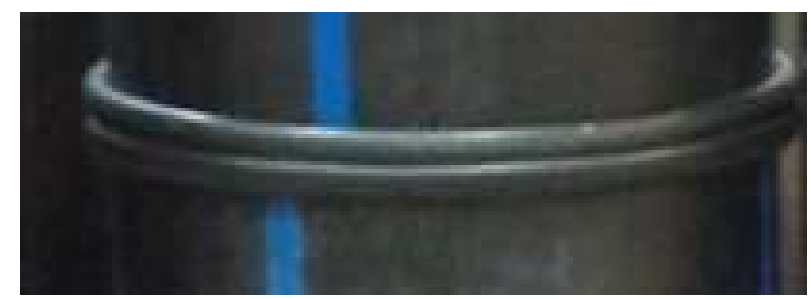

Şekil 3. Sıcak elaman alın kaynak yöntemiyle birleştirilen HDPE 100 borunun dış birleştirme bölgesi

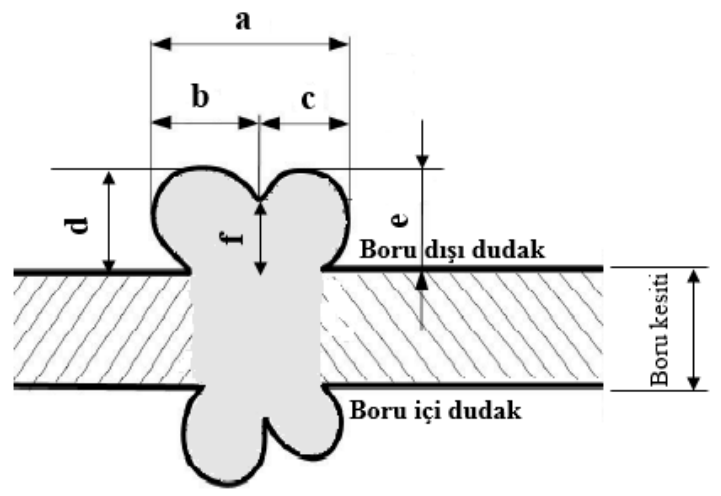

Şekil 4. Sıcak elaman alın kaynağı ile birleştirilen borularda oluşan dudak geometrisi ve adlandırılması: a: Birleştirme genişliği (toplam dudak genişliği), b: sol dudak genişliği, c: să̆ dudak genişliği, d: sol dudak yüksekliği, e: sağ dudak yüksekliği f: sağ ve sol dudaklar arası oluk yüksekliği [10]

Şekil 5 (a)'da sıcak elaman alın kaynak yöntemiyle $200^{\circ} \mathrm{C}$ kaynak sıcaklığı, Şekil 5 (b)'de $225^{\circ} \mathrm{C}$ kaynak sıcaklığı ve Şekil 5 (c)'de ise $250^{\circ} \mathrm{C}$ kaynak sıcaklığı kullanılarak birleştirilen HDPE 100 boruların iç ve dış dudak bölgelerini gösteren kesit resmi ve dudak ölçüleri verilmiştir. Kesit resimlerde görüleceği gibi kaynak sıcaklığı arttıkça, hem borunun dış hem de iç bölgelerindeki birleştirme genişliği (toplam dudak genişliği) büyümektedir. Aynı şekilde kaynak sıcaklığı arttıkça hem borunun diş hem de iç bölgelerindeki sağ ve sol dudaklar arası oluk yükseklikleri de artmaktadır. Fakat bu artış miktarları oldukça küçük seviyededir. Bu nedenle dudakların geometrik boyut ölçülerine bakarak da hangi kaynak sıcaklık değerinin daha etkin rol oynadığını söylemek mümkün olmayabilir. Yine değerlendirmenin sağlıklı yapılabilmesi için çekme deney sonuçlarına gereksinim duyulmaktadır. Çeşitli literatür çalışmalarında [11], sıcak elaman alın kaynağı ile birleştirilen PE borularda kabul edilebilir ve kabul edilemez dudak geometrisi verilmiştir. Bu veriler 1şığında bu çalışmada birleştirilen PE 100 boruların kabul edilebilir kriterler içerisinde olduğunu söylemek gerekir. Bu durum, birleştirme işleminde kullanılan kaynak parametrelerinin doğruluğunu göstermektedir. Şekil 6'da gösterildiği gibi literatürde ifade edilen sıcak elaman alın kaynağı ile birleştirilen PE borularda kabul edilebilir ve kabul edilemez dudak geometrileri verilmiştir. 


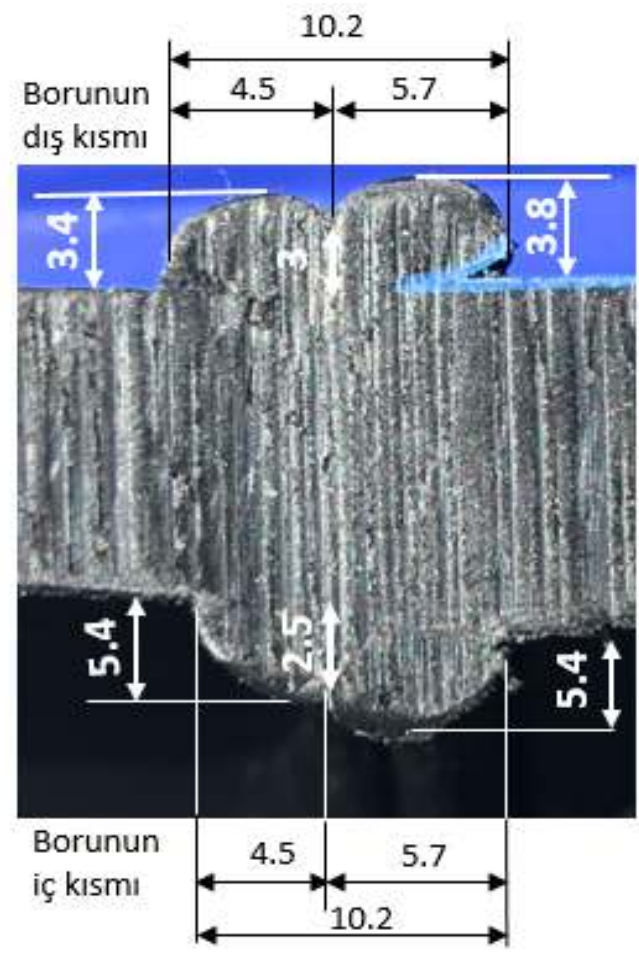

10.7

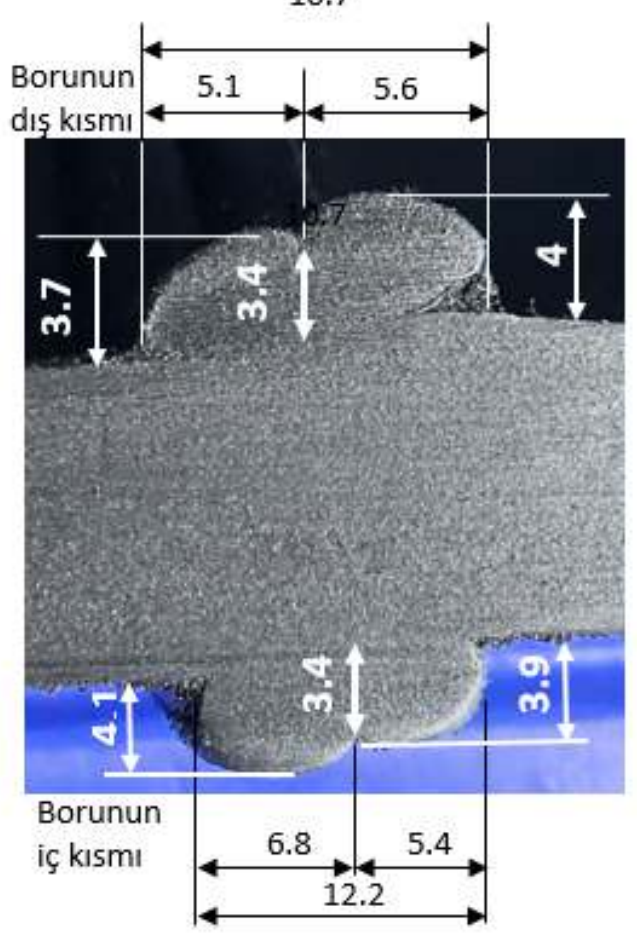

(a) Kaynak sicaklı̆ğ: $200^{\circ} \mathrm{C}$

\begin{tabular}{|l|l|l|}
\hline & $\begin{array}{c}\text { Borunun dış } \\
\text { kısmı }\end{array}$ & \multicolumn{1}{|c|}{$\begin{array}{c}\text { Borunun iç } \\
\text { kısmı }\end{array}$} \\
\hline Birleştirme genişliği & $10.2 \mathrm{~mm}$ & $10.2 \mathrm{~mm}$ \\
\hline Sol dudak genişliği & $4.5 \mathrm{~mm}$ & $4.5 \mathrm{~mm}$ \\
\hline Sağ dudak genişliği & $5.7 \mathrm{~mm}$ & $5.7 \mathrm{~mm}$ \\
\hline Sol dudak yüksekliği & $3.4 \mathrm{~mm}$ & $5.4 \mathrm{~mm}$ \\
\hline Sağ dudak yüksekliği & $3.8 \mathrm{~mm}$ & $5.4 \mathrm{~mm}$ \\
\hline $\begin{array}{l}\text { Sağ ve sol dudaklar } \\
\text { arası oluk yüksekliği }\end{array}$ & $3 \mathrm{~mm}$ & $2.5 \mathrm{~mm}$ \\
\hline
\end{tabular}

(b) Kaynak sıcaklığı: $225^{\circ} \mathrm{C}$

\begin{tabular}{|l|l|l|}
\hline & $\begin{array}{c}\text { Borunun diş } \\
\text { kısmı }\end{array}$ & $\begin{array}{c}\text { Borunun iç } \\
\text { kısmı }\end{array}$ \\
\hline Birleştirme genişliği & $10.7 \mathrm{~mm}$ & $12.2 \mathrm{~mm}$ \\
\hline Sol dudak genişliği & $5.1 \mathrm{~mm}$ & $6.8 \mathrm{~mm}$ \\
\hline Sağ dudak genişliği & $5.6 \mathrm{~mm}$ & $5.4 \mathrm{~mm}$ \\
\hline Sol dudak yüksekliği & $3.7 \mathrm{~mm}$ & $4.1 \mathrm{~mm}$ \\
\hline Sağ dudak yüksekliği & $4 \mathrm{~mm}$ & $3.9 \mathrm{~mm}$ \\
\hline $\begin{array}{l}\text { Sağ ve sol dudaklar } \\
\text { arası oluk yüksekliği }\end{array}$ & $3.4 \mathrm{~mm}$ & $3.4 \mathrm{~mm}$ \\
\hline
\end{tabular}




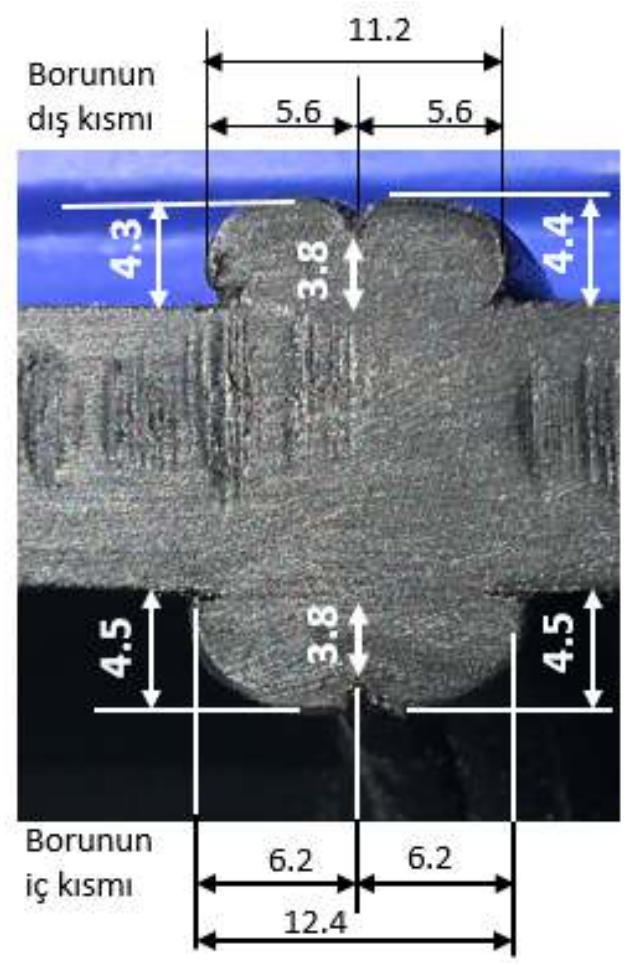

(c) Kaynak sıcaklığı: $250^{\circ} \mathrm{C}$

\begin{tabular}{|l|l|l|}
\hline & $\begin{array}{c}\text { Borunun dış } \\
\text { kısmı }\end{array}$ & $\begin{array}{c}\text { Borunun iç } \\
\text { kısmı }\end{array}$ \\
\hline Birleştirme genişliği & $11.2 \mathrm{~mm}$ & $12.4 \mathrm{~mm}$ \\
\hline Sol dudak genişliği & $5.6 \mathrm{~mm}$ & $6.2 \mathrm{~mm}$ \\
\hline Sağ dudak genişliği & $5.6 \mathrm{~mm}$ & $6.2 \mathrm{~mm}$ \\
\hline Sol dudak yüksekliği & $4.3 \mathrm{~mm}$ & $4.5 \mathrm{~mm}$ \\
\hline \begin{tabular}{l} 
Sağ dudak yüksekliği \\
\hline $\begin{array}{l}\text { Sağ ve sol dudaklar arası } \\
\text { oluk yüksekliği }\end{array}$
\end{tabular} & $3.4 \mathrm{~mm}$ & $4.5 \mathrm{~mm}$ \\
\hline
\end{tabular}

Şekil 5. Sıcak elaman alın kaynak yöntemiyle farklı kaynak sıcaklığı kullanılarak birleştirilen HDPE 100 boruların iç ve dış dudak bölgelerini gösteren kesit resmi ve dudak ölçüleri (a) Kaynak sıcaklığı, $200^{\circ} \mathrm{C}$, (b) Kaynak sıcaklığı, $225^{\circ} \mathrm{C}$ ve (c) Kaynak sicaklığ, $250^{\circ} \mathrm{C}$

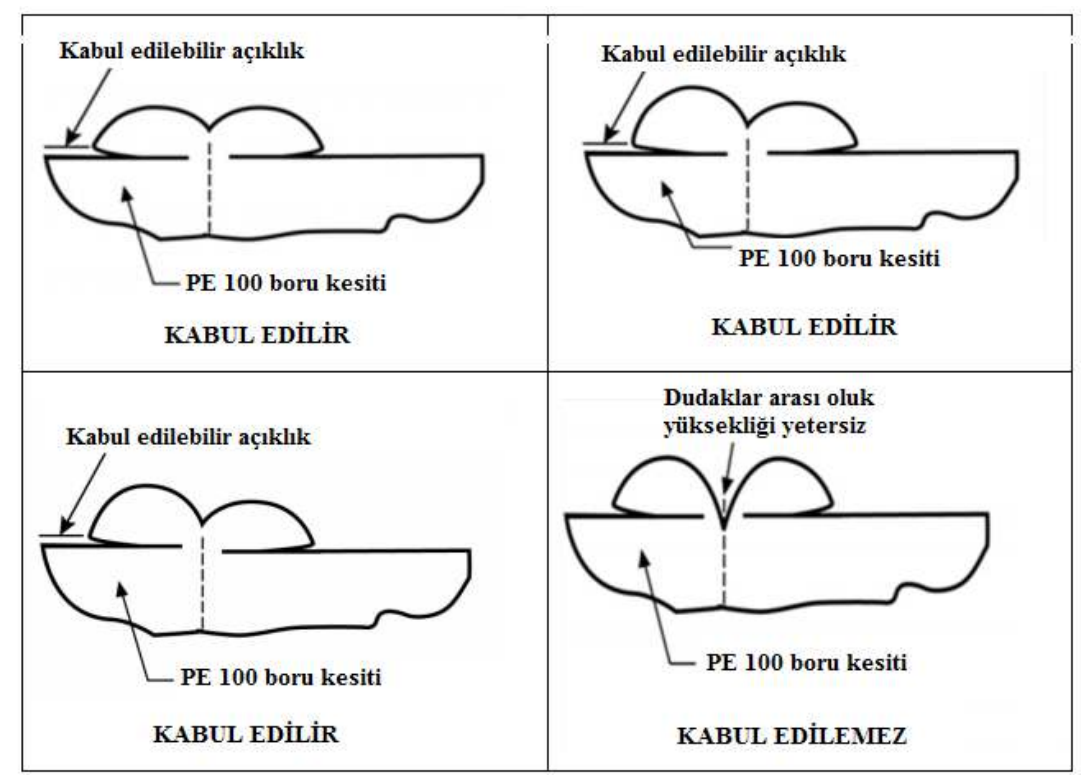

Şekil 6. Sıcak elaman alın kaynăğ ile birleştirilen PE borularda kabul edilebilir ve kabul edilemez dudak geometrileri [11] 


\section{1. Çekme deneyi sonuçları}

Şekil 7'de sıcak elaman alın kaynak yöntemiyle farklı kaynak sıcaklıklarında birleştirilen HDPE 100 boruların kaynak bölgelerine ait çekme - \% uzama eğrileri gösterilmekte ve Tablo 3 'de de sayısal çekme deney sonuçları verilmektedir. Çekme deneyi sonuçlarına göre, kaynak sıcaklığının haricindeki kaynak parametrelerinin sabit tutulduğu birleştirme işleminde, kaynak sıcaklığ $1225^{\circ} \mathrm{C}$ olarak seçilen birleştirmede, diğerlerine göre daha yüksek çekme mukavemeti değeri elde edilmiştir. Çekme deneyi sonuçları ile dudak geometri ölçüleri beraberce değerlendirildiğinde, optimum birleştirme mukavemetinin sağlanabilmesi için kaynak sıcaklığının $225^{\circ} \mathrm{C}$ olarak seçilmesi öngörülmüştür.

Şekil 8'da Literatürde sıcak elaman kaynak tekniğiyle birleştirilecek boruların et kalınlığı dikkate alınarak kaynak sıcaklığı önerisinde bulunulan grafik verilmiştir. Bu grafikte $10 \mathrm{~mm}$ et kalınlığına sahip PE boru için $210^{\circ} \mathrm{C}$ 'lik bir kaynak sıcaklığı önerilmiştir. Bu çalışmamızda ise, et kalınlığ 10 mm olan PE 100 borunun sıcak eleman kaynağı ile birleştirilmesinde Tablo 2'de verilen sabit kaynak parametreleriyle birlikte, en uygun kaynak sıcaklığının $225^{\circ} \mathrm{C}$ olduğu tespit edilmiştir.

Şekil 9'de ise çekme deneyi sonucu kopan numunelerin kopma bölgelerine ait resimleri gösterilmektedir.

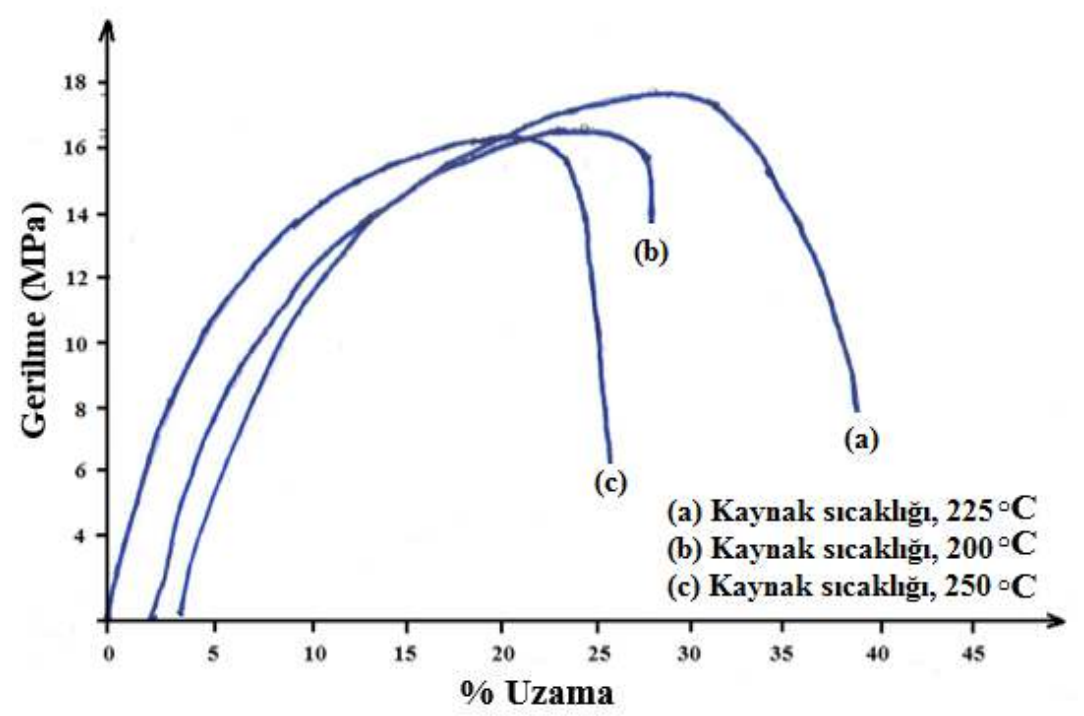

Şekil 7. Sıcak elaman alın kaynak yöntemiyle farklı kaynak sıcaklıklarında birleştirilen HDPE 100 boruların kaynak bölgelerine ait çekme - \% uzama eğrileri 
Tablo 3. Çekme deney sonuçları

\begin{tabular}{cccc}
\hline $\begin{array}{c}\text { Kaynak sıcaklığ } \\
\mathrm{T}\left({ }^{\circ} \mathrm{C}\right)\end{array}$ & $\begin{array}{c}\text { Akma Mukavemeti } \\
(\mathrm{MPa})\end{array}$ & $\begin{array}{c}\text { Çekme Mukavemeti } \\
(\mathrm{MPa})\end{array}$ & $\begin{array}{c}\text { Çekme } \\
\text { Mukavemetindeki } \\
\text { \% Uzama }\end{array}$ \\
\hline 200 & 9 & 16.5 & 23 \\
225 & 11 & 18 & 28 \\
250 & 10 & 16 & 20 \\
\hline
\end{tabular}

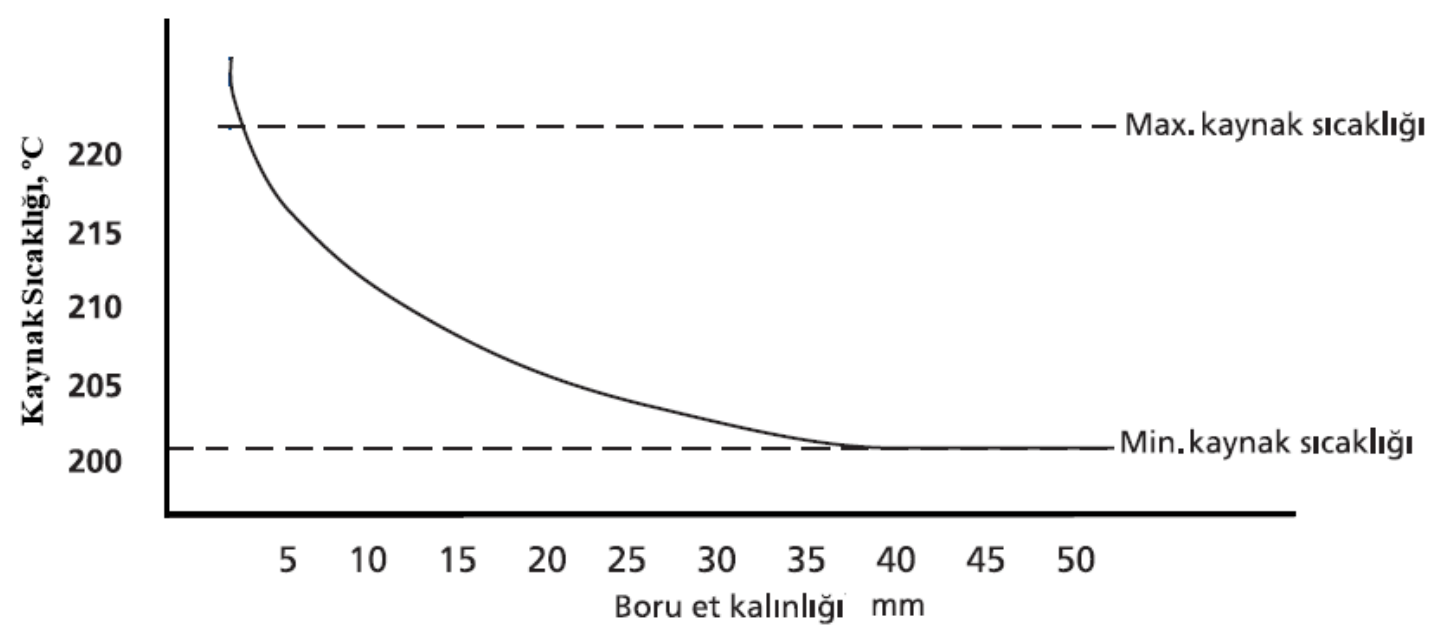

Şekil 8. Sıcak eleman kaynağı için boru et kalınlığına göre önerilen kaynak sıcaklık grafiği [12]

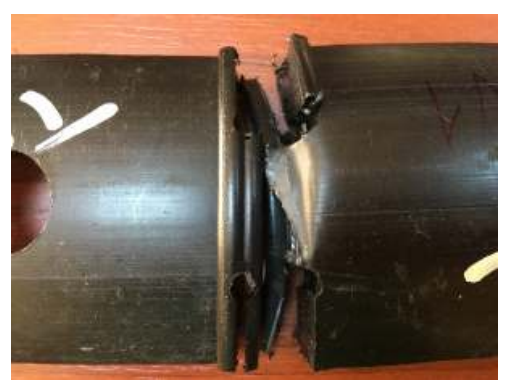

(a)

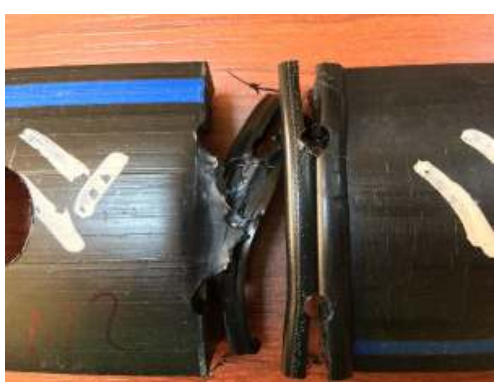

(b)

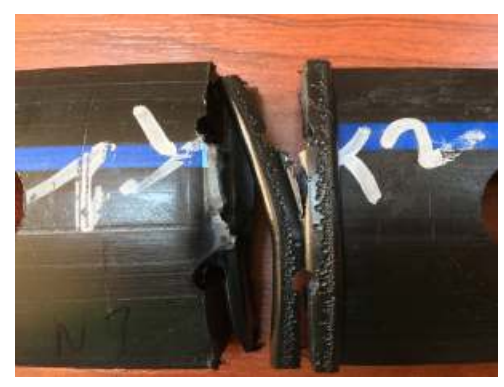

(c)

Şekil 9. Çekme deneyi sonucu kopan numunelerin görünümü (a) Kaynak sıcaklı̆̆ı, $200^{\circ} \mathrm{C}$, (b) Kaynak sıcaklığ 1 , $225^{\circ} \mathrm{C}$ ve (c) Kaynak sicaklığı, $250^{\circ} \mathrm{C}$.

\section{Sonuçlar}

Bu çalışmada, doğal gaz ve içme suyu dağıtım hatlarında, metalik boruların yerini alan yüksek yoğunluklu PE 100 boruların, sıcak elaman alın kaynağı yöntemiyle farklı kaynak sıcaklıkları kullanılarak başarıyla birleştirilmiştir. Birleştirme mukavemetine göre, kaynak parametreleriyle 
uyumlu en uygun optimum kaynak sıcaklık değerinin belirlenmesi amacıyla ilgili araştırmadan elde edilen genel sonuçlar aşağıda verilmiştir.

1. Aynı özellik ve aynı çaptaki HDPE 100 boruların sıcak eleman kaynak yöntemiyle birleştirilmesi uygun kaynak parametreleri seçilmek şartıyla mümkündür.

2. HDPE 100 boruların sıcak eleman alın kaynak yöntemiyle başarılı bir şekilde birleştirilmesi için yanaştırma ve birleştirme basınçları 6 bar, 1sıtıcının yanaştırma süresi 25 sn, 1sıtma süresi $120 \mathrm{sn}$, isıtıcının çıkartılma süresi $6 \mathrm{sn}$, birleştirme süresi 6 sn ve basınç altında soğuma süresi 12 sn ve kaynak sıcaklığının da $225^{\circ} \mathrm{C}$ olarak seçilmesi gerektiği tespit edilmiştir.

\section{Teşekkür}

$\mathrm{Bu}$ çalışmada emeği geçen, NTG Plastik yönetici ve çalışanlarına teşekkür ederiz.

\section{Kaynaklar}

[1] Kalde Klima Aş., PE100 Teknik katalog, http://www.kalde.com/cdn/archive/document/65/p100_teknik_katalog_2015turkce.pdf, 2018;1-2.

[2] Pakpen, Altyapı Boru sistemleri, http://www.pakplast.com.tr/index.asp?action=pe_boru_ustunlukleri, 2018;2-3.

[3] Fırat, Basınçlı Polietilen Boru sistemleri Teknik Kataloğu, http://www.firat.com/cmsfiles/certificates/9897/pe-100-teknik-katalogu-2.pdf, 2018;29.

[4] Çelikkan O, Yüksek yoğunluklu polietilenin vizkoelastik özelliklerinin deneysel incelenmesi, Yüksek Lisans Tezi, İTÜ, Şubat 2011.

[5] Akkurt A, An analysis of electro-melting and hot element welding methods' safety used to join PE natural gas pipes, Int. Journal of Elect. Mech. Mechatronics Eng., Ocak 2013; 3, 2493-504.

[6] Runčev D, Trpkovski Lj. Heated tool butt welding of PE pipes, 8. Int. Conf. Advanced Manufacturing Operations, 2008;21-25.

[7] Akkurt A, Ertürk İ, Sıcak eleman alın kaynak yöntemi ile birleştirlen PE doğalgaz boruların güvenirliklerinin araştırılması, PÜ Mühendislik Bilimleri Dergisi, 2010;16,2,221-233.

[8] NTG Plastik, Teknik el kitabı, http://ntgplastik.com/uploads/pdf/NTG_TeknikKitap_TR2.pdf, 2018;32-38.

[9] Akkurt A, Saraç E, Sıcak alın kaynak yöntemi ile farklı sıcaklıklarda birleştirlen PE doğalgaz transfer hatlarının güvenirliklerinin araştırılması, PÜ Mühendislik Bilimleri Dergisi, 2015;21,1,15-23.

[10] Werner K, Jaruga T, Baranowski W, Kula M, Evaluation of Cracking Conditions of Butt Welded Joints in Polyethylene Pipes, PRZETWÓRSTWO TWORZYW 1, 2016;36-42.

[11] The Plastics Pipe Institute, Inc., Recommended Minimum Training Guidelines for PE Pipe Butt Fusion Joining Operators for Municipal and Industrial Projects TN-42, March 2013.

[12] Anık S, Dikicioğlu A, Vural M. Termoplastik malzemelerin kaynağı. Kaynak Tekniği Derneği. İkinci Baskı. İstanbul, Türkiye, Birsen Yayınevi, 1994. 